\title{
IMPLEMENTASI KOMUNIKASI FULL DUPLEX MENGGUNAKAN WEB SOCKET PADA SISTEM INFORMASI PENGELOLAAN ANGGARAN UNIVERSITAS ABC
}

\author{
Husen \\ Fakultas Teknik, Program Studi Teknik Informatika \\ Universitas Siliwangi \\ Email: husen@student.unsil.ac.id \\ Alam Rahmatulloh \\ Fakultas Teknik, Program Studi Teknik Informatika \\ Universitas Siliwangi \\ Email: alam@unsil.ac.id \\ Heni Sulastri \\ Fakultas Teknik, Program Studi Teknik Informatika \\ Universitas Siliwangi \\ Email: heni.sulastri@unsil.ac.id
}

\begin{abstract}
ABSTRAK
Penelitian ini membahas mengenai sistem pengelolaan anggaran di Universitas ABC yang didalamnya memuat manajemen pengelolaan anggaran biaya dari setiap bagian mulai dari pengajuan rencana anggaran biaya sampai dengan realisasi anggaran. Data dari hasil pengelolaan anggaran setiap bagian dapat dimonitoring oleh pihak pimpinan, namun dalam penyajian datanya belum real-time sehingga interaksi user dalam monitoring dan analisis data pada sistem kurang interaktif. Saat ini teknologi yang sedang tren pada aplikasi berbasis web yang real-time yaitu web socket (WS). WS dapat menyajikan komunikasi dua arah secara bersamaan (full-duplex). Selain itu menurut beberapa penelitian teknologi WS juga dapat meningkatkan performa sistem menjadi lebih baik. Maka pada penelitian ini akan di terapkan teknologi web socket sehingga proses monitoring data anggaran dapat dilakukan secara real-time dengan menyajikan data tersebut ke dalam bentuk grafik dan persentase. Hasil penelitian yang dilakukan menunjukan bahwa dengan menggunakan WS nilai perbandingan Round Trip Time (RTT) yaitu 1:135 ms jika dibandingakan ajax, sehingga penggunaan teknologi WS lebih cepat dan performanya jauh lebih baik.
\end{abstract}

Kata Kunci: anggaran, full-duplex, monitoring, real-time, web socket.

\begin{abstract}
This study discusses the budget management system at ABC University which includes the management of budget cost management from each unit starting from the submission of a budget plan to budget until the realization of the budget. Data from the budget management results of each section can be monitored by the leadership, but in the presentation of the data has not been real-time so that user interaction in monitoring and data analysis on the system is less interactive. Currently trending technology in real-time web-based applications is web socket (WS). WS can present two-way communication simultaneously (full-duplex). In addition, according to some research WS technology can also improve system performance for the better. So in this study will be applied Web Socket technology so that the process of monitored budget data can be done in real-time by presenting the data in the form of graphs and percentages. The result of the research shows that by using WS Round Trip Time (RTT) value is 1: 135 ms if compared ajax, so the use of WS technology is faster and its performance is much better.
\end{abstract}

Keywords: budget, full-duplex, monitored, real-time, web socket.

\section{PENDAHULUAN}

Pengelolaan anggaran merupakan suatu permasalahan yang umum terjadi di berbagai bidang ilmu, terjadi akibat tidak adanya manajemen anggaran yang baik, terencana, terukur dan realisasi dapat dipantau [1]. Untuk itu dibutuhakan sebuah sistem dalam mengatasi permasalahan tersebut, seperti halnya di Universitas ABC yang sudah menggunakan sistem pengelolaan anggaran yang didalamnya mengelola data 
Rencana Anggaran Biaya (RAB) yang dapat di monitoring oleh pihak pimpinan. Namun masih terdapat kendala dalam segi penyajian data yang masih menggunakan sistem satu arah (simplex) [2] sehingga belum real-time dan performa sistem yang masih lambat. Maka dibutuhkan penyajian data yang real-time untuk memonitoring hasil anggaran yang di serap atau yang direalisasikan sehingga meningkatkan performa sistem dan mendukung pihak pemimpin dalam memonitoring serta menganalisis hasil dari pengelolaan anggaran. Dengan menerapkan transmisi full-duplex, dua station secara simultan mengirim dan menerima satu sama lain. Sehingga model ini disebut juga two-way simultaneous dan bisa diibaratkan sebagai duajalur, dua-jembatan [3]. Teknologi pada aplikasi berbasis web yaitu Asynchronous JavaScript and XML (AJAX) dan websocket merupakan teknologi yang dapat menyajikan data secara real-time, namun AJAX memiliki kekurangan dalam meningkatkan performa sistem dibandingan websocket. Sedangkan websocket merupakan teknologi yang dianggap akan banyak digunakan dalam penyajian data real-time menggantikan ajax [4]. Websocket merupakan protokol komunikasi full-duplex (dua arah secara bersamaan) melalui koneksi TCP, ditujukan untuk melakukan pertukaran pesan antar browser dan server web secara real-time [5]. Websocket dapat meningkatkan performa sistem, hal ini mengurangi beban jaringan bila dibandingkan dengan metode konvensional. Teknologi websocket sering digunakan saat komunikasi data dua arah. Secara khusus, efek positif dari penggunaan teknologi websocket lebih terasa saat menggunakan aplikasi web berbasis komunikasi data dua arah real-time [6]. Sehingga dalam penelitian ini akan menerapkan teknologi websocket dalam penyajian data pengelolaan RAB secara real-time. Tujuan dari penelitian ini adalah menyajikan data kedalam bentuk grafik dan persentase secara real-time agar memudahkan pihak pimpinan dalam memonitoring data anggaran.

\section{METODOLOGI PENELITIAN}

\subsection{Pengumpulan Data}

\subsubsection{Wawancara}

Wawancara (Interview), wawancara merupakan teknik pengumpulan data dengan cara bertatap muka langsung dengan narasumber untuk saling bertukar informasi melalui proses tanya jawab, sehingga dapat menarik sebuah kesimpulan tentang permasalahan yang ada.

\subsubsection{Observasi}

Observasi merupakan teknik pengumpulan data, dengan cara melakukan pengamatan langsung terhadap objek penelitian agar dapat melihat kegiatan yang dilakukan.

\subsubsection{Pengembangan Perangkat Lunak}

Metodologi pengembangan perangkat lunak pada penelitian ini menggunakan RUP (Rational Unified Process). Metode RUP memiliki empat fase, yaitu inception, elaboration, construction dan transition.

\subsubsection{Inception}

Pada tahap pertama ini dilakukan proses business modelling yaitu memodelkan suatu proses bisnis yang dibutuhkan kemudian mendefinisikan kebuatuhan suatu sistem (requirements).

\subsubsection{Elaboration}

Pada tahapan kedua lebih difokuskan terhadap perencanaan arsitektur sistem seperti melakukan anlisis sistem dan desain sistem.

\subsubsection{Construction}

Pada tahap ketiga dilakukan pengembangan komponen dan fitur-fitur sistem serta melakukan implementasi dan pengujian sistem yang fokus terhadap implementasi perangkat lunak pada kode program. 


\subsubsection{Transition}

Tahap yang terakhir melakukan deployment atau installasi sistem yang bertujuan untuk penerapan sistem dan pelatihan kepada pengguna sistem serta pemeliharan sistem.

\section{HASIL DAN PEMBAHASAN}

\subsection{Pengumpulan Data}

\subsubsection{Wawancara}

Hasil dari melakukan wawancara yang dilakukan dengan proses tanya jawab kepada narasumber di tempat penelitian, maka ada beberapa masalah yang sedang terjadi di dalam proses pengelolaan perencanaan anggaran diantaranya:

a. Dalam penyajian data hasil pengelolaan anggara dari setiap unit masih disajikan secara manual yaitu ketika admin ingin mendapatkan data yang terbaru dari hasil pengelolaan anggaran maka harus dilakukan reload page terlebih dahulu sehingga monitoring yang dilakukan kurang interaktif.

b. Sistem masih menggunakan ajax dalam menangani permasalahan real-time data sehingga performa sistem menjadi menurun.

\subsubsection{Observasi}

Hasil dari pengumpulan data dengan melakukan observasi dapat menyimpulkan beberapa kegiatan diantaranya sebagai berikut :

a. Diperlukannya penyajian data secara real-time pada dashboard admin, sehingga mendukung dalam proses monitoring dan analisis anggaran yang diajukan dan direalisasikan dari setiap unit.

b. Diperlukannya komunikasi full-duplex untuk mengatasi permasalahan penyajian real-time data dan peningkatan performa sistem.

\subsection{Pengembangan Perangkat Lunak}

\subsubsection{Inception}

a. Identifikasi Penyebab Masalah

Pada sistem pengelolaan anggaran yang sedang berjalan di Universitas ABC ini terdapat beberapa user yang berperan di dalam sistem tersebut. User admin selaku pihak pimpinan dapat melakukan monitoring hasil dari pengelolaan data anggaran seperti serapan biaya anggaran, pengajuan anggaran serta realisasi anggaran yang dilakuan oleh setiap user unit. Namun dalam penyajian data di dashboard admin masih belum real-time sehingga ketika ada informasi yang terbaru admin harus reload halaman dashboard tersebut dan ini merupakan suatu kendala dalam memonitoring data anggaran yang sedang berjalan.

b. Sistem Usulan

Sistem yang diusulkan dalam permasalahan penyajian data secara real-time ini yaitu ketika unit melakukan pengajuan yang ada maka dalam waktu yang bersamaan informasi penyerapan yang dilakukan oleh unit akan langsung di ketahui oleh admin dengan bentuk tampilan persentase atau grafik secara real-time, begitupun saat unit melakukan realisasi.

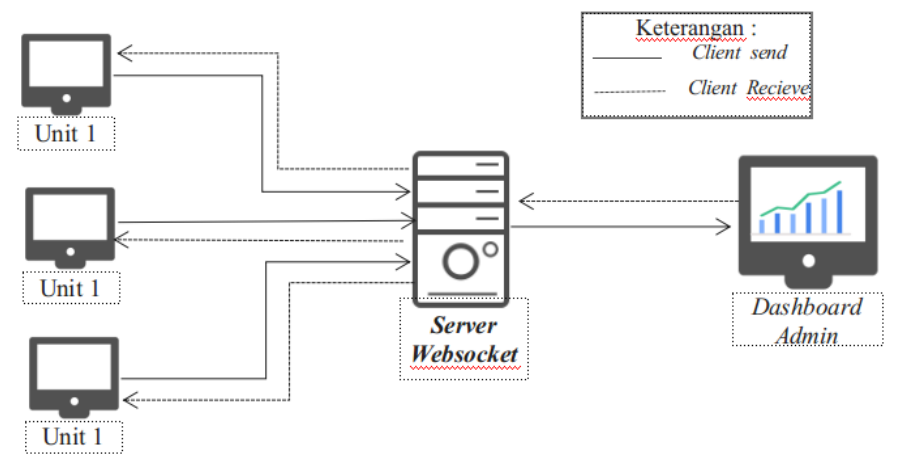

Gambar 1. Sistem Usulan Dengan Menerapkan Komunikasi Full-Duplex 
Pada gambar 1 merupakan gambaran sistem usulan dengan menerapkan teknologi websocket untuk merubah komunikasi secara full-duplex pada saat melakukan proses penyerapan biaya atau realisasi yang dilakukan unit dan langsung dapat dimonitoring oleh admin secara real-time.

\subsubsection{Elaboration}

a. Identifikasi Use Case

Pada tabel 1 merupakan penjelasan dari beberapa use case dari sistem pengelolaan anggaran.

Tabel 1. Daftar use case

\begin{tabular}{cc}
\hline Aktor & Aktivitas \\
\hline 1. Admin & Monitoring Data \\
& Melakukan Finalisasi \\
2. Unit & Mengajukan RAB \\
& Mengajukan Realisasi \\
3. Verifikator & Verifikasi Realisasi \\
4. Bendahara & Mengecek Realisasi \\
5. Rekonsiliasi & Acc Realisasi \\
\hline
\end{tabular}

Pada Gambar 2 merupakan gambar hubungan dari masing - masing use case yang ada pada sistem pengelolaan anggaran dengan memiliki 5 aktor yang saling berinteraksi pada sistem.

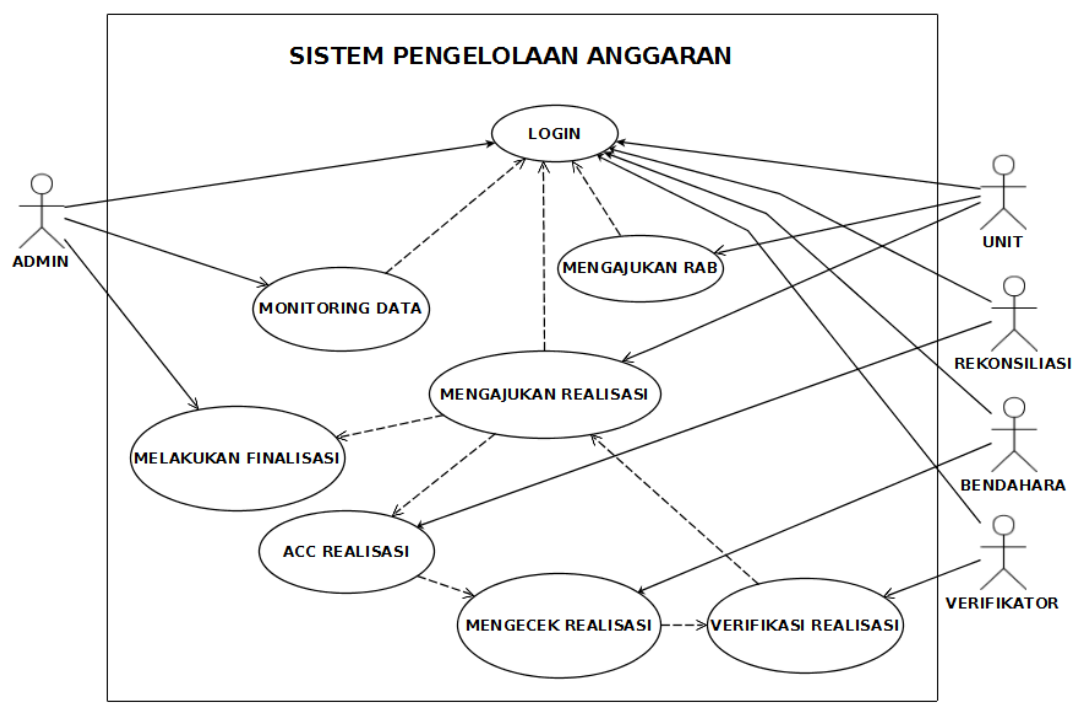

Gambar 2. Use Case Diagram

b. Perancangan Antarmuka

Rancangan antarmuka pada sistem pengelolaan anggaran dengan komunikasi full-duplex ini adalah sebagai berikut :

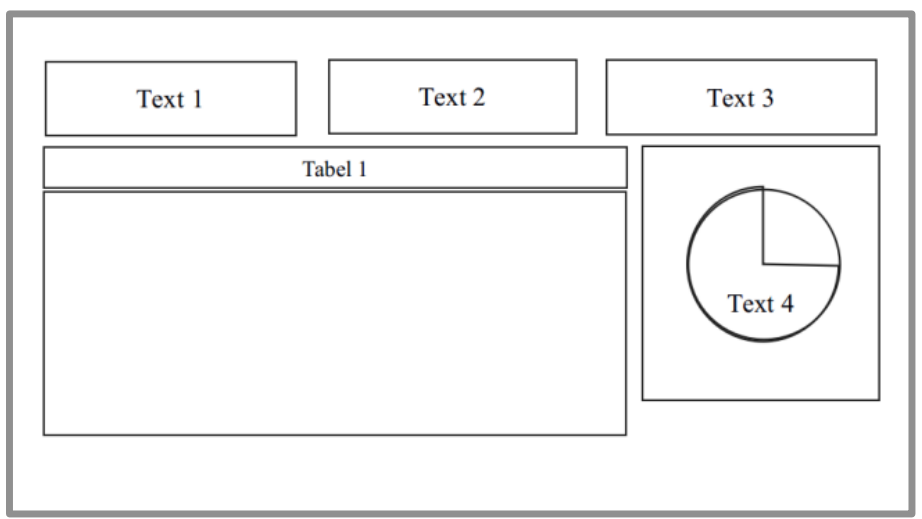

Gambar 3. Antarmuka Dashboard Admin 
Pada gambar 3 merupakan rancangan antramuka dashboard admin yaitu text 1 merupakan info dari sisa pagu, text 2 adalah info serapan, text 3 info realisasi, text 4 info grafik pengajuan dan table 1 adalah rekap data $\mathrm{RAB}$ per output.

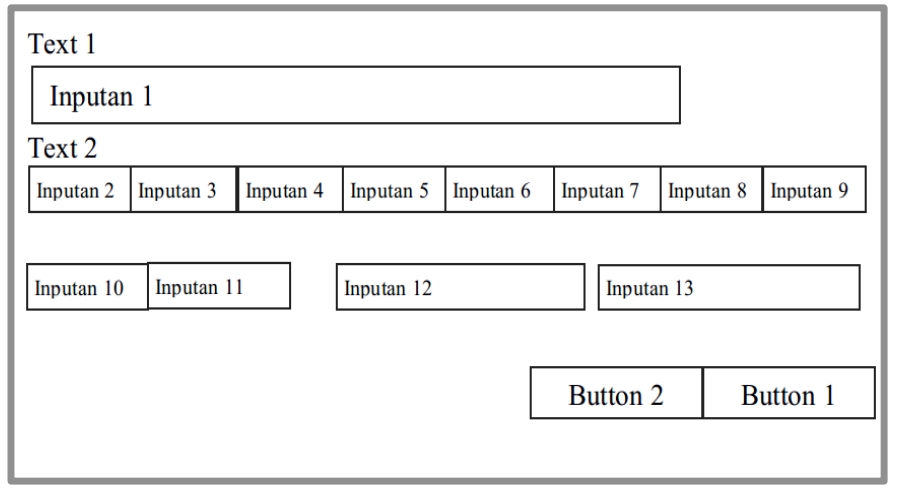

Gambar 4. Antarmuka Inputan Rincian Biaya

Pada gambar 4 merupakan rancangan antarmuka pengisian rincian biaya yaitu inputan 1 adalah keterangan rincian biaya, inputan 2,4,6,8 adalah volume rincian biaya, inputan 3,5,7,9 dan 11 adalah satuan kegiatan, inputan 10 total keseluruhan volume, inputan 12 isisan biaya, inputan 13 total dari jumlah volume di kalikan dengan biaya, button 1 tombol untuk menyimpan dan button 2 tombol untuk membatalkan.

\subsubsection{Construction}

a. Implementasi script di sisi server

Dalam menjalankan server websocket ini hal yang pertama harus dilakukan adalah mengaktifkannya melalui PHP CLI (Command Line Interface) agar dapat mengirim pesan dan menerima pesan dengan perintah php server.php pada terminal. Adapun isi file dari server.php dapat dilihat pada gambar 5 .

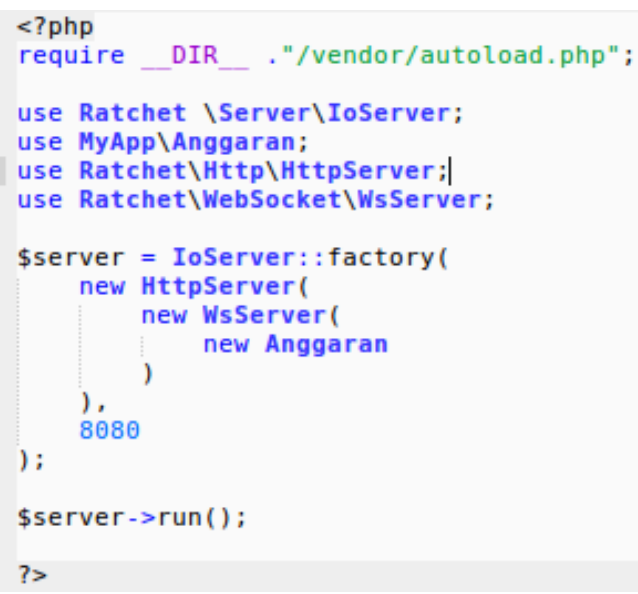

Gambar 5. Script Server Websocket

Pada server websocket ini port yang digunakan yaitu port 8080 seperti yang terlihat di gambar 6 pada baris ke 15. Perintah \$server->run() pada baris ke 18 berfungsi untuk menjalankan library Ratchet dan class Anggaran yang merupakan konfigurasi utama dari aplikasi websocket server. Adapun script dari class Anggaran dapat dilihat pada gambar 6. 


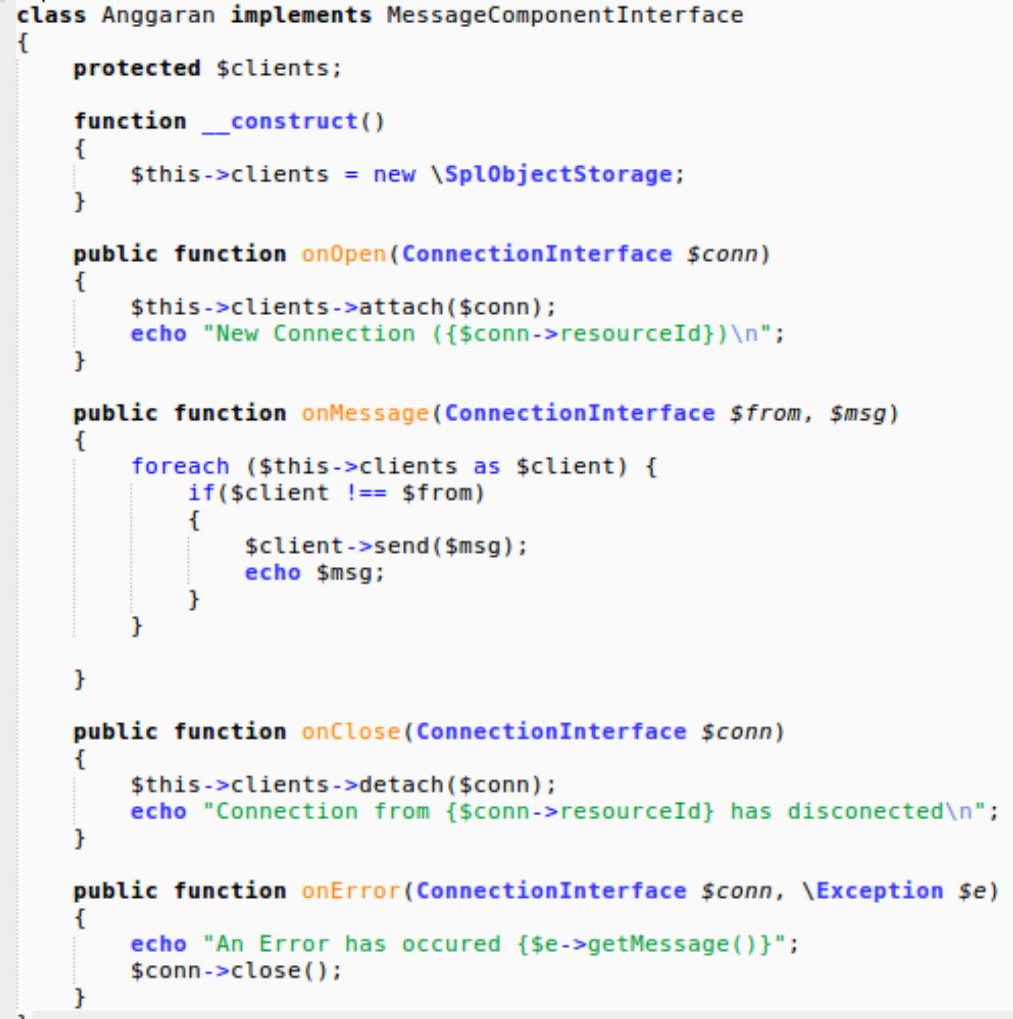

Gambar 6. Script Websocket Class Anggaran

Pada gambar 6 terdapat 4 fungsi yaitu onopen(), onMessage(), onclose() dan onError () . Pada fungsi onOpen () ini akan menampilkan resourcelD dari setiap client yang terhubung pada server websocket, sedangkan fungsi onMessage () menangani ketika terjadinya pengiriman atau penerimaan pesan dari client kepada client yang lain berdasarkan id client tersebut secara real-time. pada fungsi onclose(), fungsi ini akan menampilkan pemberitahuan dari client yang telah keluar dari koneksi terhadap server websocket. Sedangkan fungsi yang terakhir yaitu fungsi onError () akan menampilkan pesan kesalahan ketika terjadi error.

b. Implementasi script di sisi client

Pada penelitian ini client menggunakan bahasa pemrograman javascript dalam melakukan koneksi terhadap server websocket. Pada javascript terdapat object khusus untuk terkoneksi kepada server websocket yaitu dengan menggunakan perintah new Websocket('ws://url:port') adapun script yang di implementasikan pada aplikasi pengelolaan anggaran ini bisa dilihat pada gambar 7.

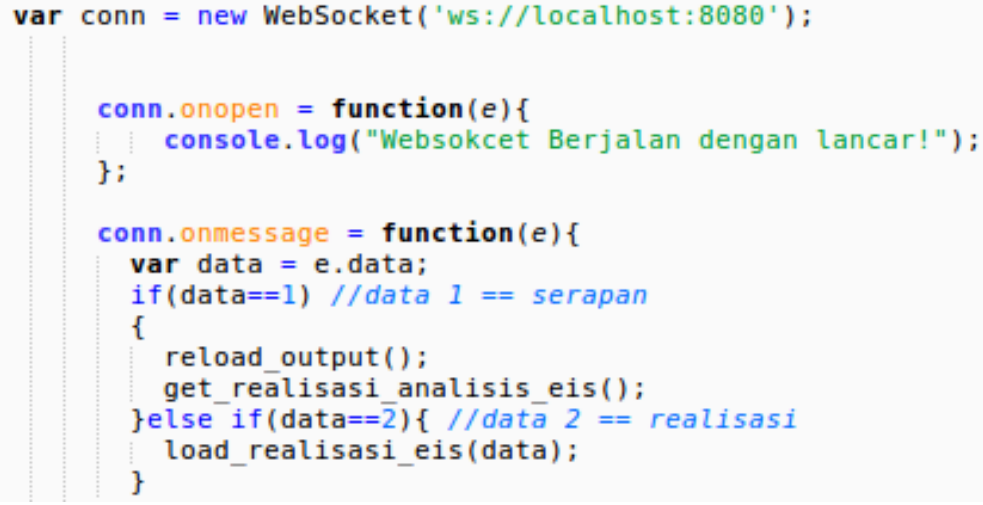

Gambar 7. Implementasi Script Websocket Di Sisi Client 
Pada gambar 7 di baris 6 merupakan perintah untuk melakukan koneksi ke server websocket. Sedangkan pada baris 8 - 11 merupakan perintah untuk menampilkan pesan ketika client berhasil terkoneksi dengan server websocket.

c. Implementasi Perangkat Lunak

Implementasi perangkat lunak pada sistem pengelolaan anggaran dengan komunikasi full-duplex ini adalah sebagai berikut :

d. Implementasi dashboard admin

Tampilan dashboard admin berfungsi menampilkan informasi yang berhubungan dengan proses penyusunan anggaran seperti presentase serapan biaya, realisasi dan pagu yang tersisa seperti pada gambar 8 .

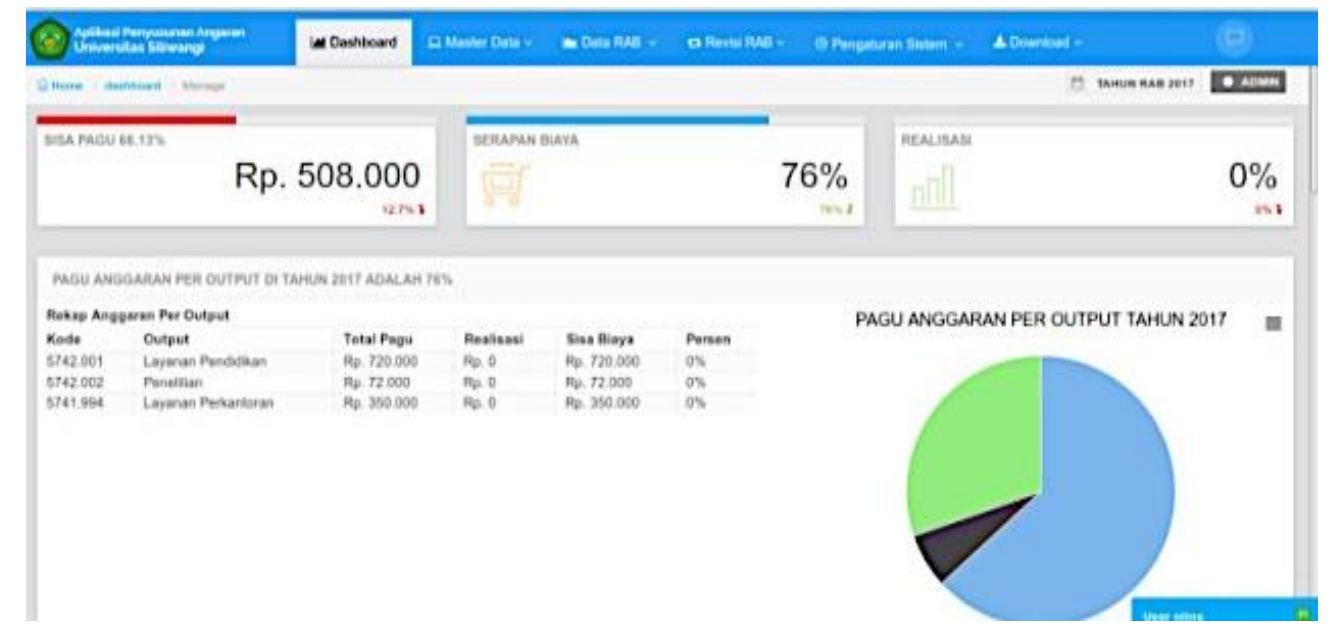

Gambar 8. Dashboard Admin

e. Implementasi pengajuan $\mathrm{RAB}$

Tampilan saat unit mengisi rincian biaya untuk melakukan pengajuan RAB bisa di lihat pada gambar 9.

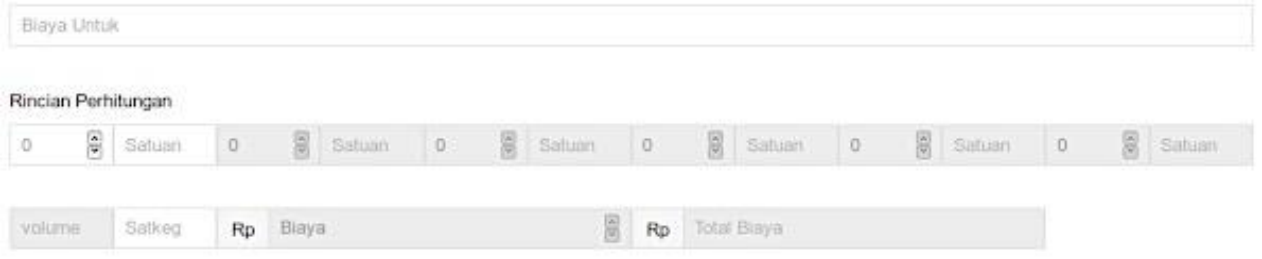

\section{Gambar 9. Proses Pengisian Rincian Biaya}

Pada gambar 9 unit mengisi formulir isian rincian biaya untuk melakukan pengajuan RAB. Ketika unit menekan tombol simpan, maka rincian biaya akan tersimpan dan jumlah biaya pengajuan RAB otomatis akan terupdate di dashboard admin secara real-time dalam bentuk presentase atau grafik.

\subsubsection{Transition}

Pada tahap ini dilakukan pengujian nilai Round Trip Time (RTT) terhadap teknologi websocket dan dibandingkan dengan ajax. RTT adalah waktu yang dibutuhkan sebuah paket untuk melakukan perjalanan dari sumber ke tujuan dan kembali lagi. RTT merupakan ukuran penting dalam menentukan penuhnya suatu koneksi [7]. Nilai RTT sangat tergantung dari kondisi trafik. Semakin padat trafik maka semakin besar RTT yang dihasilkan [8]. 
Tabel 2. Nilai round trip time websocket

\begin{tabular}{cccc}
\hline \multicolumn{4}{c}{ Round Trip Time Websocket } \\
\hline No & Send $(\boldsymbol{m s})$ & Receive $(\boldsymbol{m s})$ & RTT $(\boldsymbol{m s})$ \\
\hline 1 & 894 & 895 & 1 \\
2 & 132 & 134 & 2 \\
3 & 99 & 100 & 1 \\
4 & 359 & 360 & 1 \\
5 & 889 & 890 & 1 \\
6 & 826 & 827 & 1 \\
7 & 103 & 104 & 1 \\
8 & 574 & 576 & 2 \\
9 & 524 & 525 & 1 \\
10 & 841 & 842 & 1 \\
11 & 772 & 773 & 1 \\
12 & 353 & 355 & 2 \\
13 & 849 & 850 & 1 \\
14 & 853 & 853 & 0 \\
15 & 149 & 150 & 1 \\
\hline $\boldsymbol{A V G}$ & $\mathbf{5 4 7 . 8}$ & $\mathbf{5 4 8 . 9}$ & $\mathbf{1 . 1 3}$ \\
\hline
\end{tabular}

Pada tabel 2 terlihat bahwa pengujian terhadap websocket dengan waktu rata-rata pengiriman (send) $547.8 \mathrm{~ms}$ dan penerimaan (receive) adalah $548.9 \mathrm{~ms}$ sedangkan waktu RTT sangat rendah dengan nilai rata rata $1.13 \mathrm{~ms}$, karena itu websocket sangat mendukung dalam peningkatan performa sistem.

Tabel 3. Nilai round trip time ajax

\begin{tabular}{cccc}
\hline \multicolumn{4}{c}{ Round Trip Time Websocket } \\
\hline No & Send $(\boldsymbol{m s})$ & Receive $(\boldsymbol{m s})$ & RTT $(\boldsymbol{m s})$ \\
\hline 1 & 626 & 767 & 141 \\
2 & 321 & 448 & 127 \\
3 & 637 & 755 & 118 \\
4 & 661 & 774 & 113 \\
5 & 804 & 929 & 125 \\
6 & 206 & 334 & 128 \\
7 & 326 & 455 & 129 \\
8 & 126 & 273 & 147 \\
9 & 608 & 765 & 157 \\
10 & 747 & 897 & 150 \\
11 & 155 & 300 & 145 \\
12 & 368 & 500 & 132 \\
13 & 302 & 459 & 157 \\
14 & 327 & 457 & 130 \\
15 & 147 & 275 & 128 \\
\hline $\boldsymbol{A V G}$ & $\mathbf{4 2 4 . 0 7}$ & $\mathbf{5 5 9 . 2}$ & $\mathbf{1 3 5 . 1 3}$ \\
\hline
\end{tabular}

Terlihat ada tabel 3 bahwa pengujian dengan teknologi sebelumnya yang dalam hal ini dicoba menggunakan ajax didapatkan nilai rata-rata request adalah $424.07 \mathrm{~ms}$ dan response adalah $559.2 \mathrm{~ms}$, sedangkan nilai rata-rata dari RTT sangat besar dibandingan dengan nilai RTT pada websocket yaitu 135.13 $m s$. 


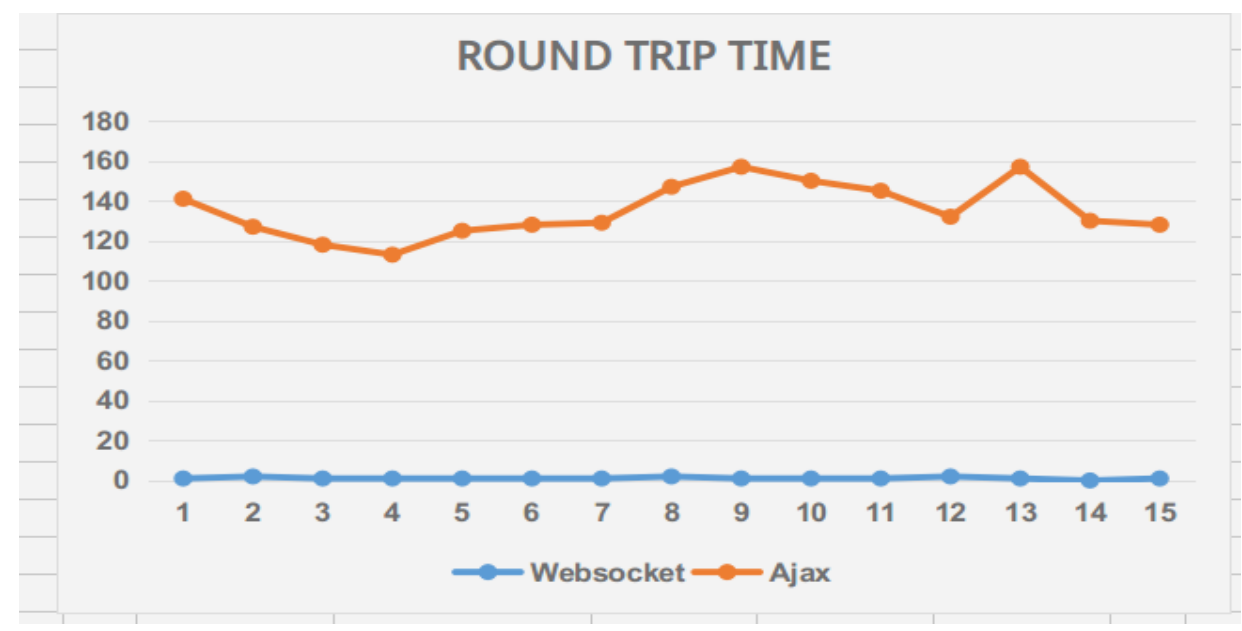

Gambar 10. Perbandingan RTT Websocket dan Ajax

Pada gambar10 merupakan gambar grafik perbandingan dari nilai RTT antar websocket dan ajax. Pada pengujian ini terlihat bahwa nilai RTT dari webscoket sangat rendah dibandingkan dengan ajax dan ratarata waktu RTT nya pun stabil dibandingan dengan ajax.

\subsection{Kelebihan Dan Kekurangan}

Kelebihan dari sistem yang sudah dibangun:

a. Tampilan sistem atau aplikasi responsive saat di buka di perangkat mobile

b. Sistem monitoring menjadi lebih interaktif dengan kinerja sistem yang lebih baik sehingga mudah digunakan dan dipahami oleh user

Adapun kekuranganya saat mengaktifkan server websocket masih manual yaitu dengan mengetikan terlebih dahulu perintah pada $p h p$ cli.

\section{KESIMPULAN}

Berdasarkan hasil penelitian yang telah dilakukan di Universitas ABC dapat diambil kesimpulan bahwa telah berhasil dibuat sebuah sistem yang dapat menyajikan data secara real-time menggunakan komunikasi full-duplex menggunakan teknologi websocket dengan nilai latency lebih cepat 1:135 ms dibandingan dengan ajax. Sistem ini dapat membantu pihak pimpinan atau admin dalam melakukan monitoring dan menganalisis data anggaran yang disajikan dalam bentuk grafik dan persentase secara realtime. Dengan menerapkan teknologi websocket juga dapat meningkatkan performa sistem yang lebih baik.

\section{DAFTAR PUSTAKA}

[1] A. Rahmatulloh and Husen, "Sistem Informasi Manajemen Anggaran (Simangga) Perguruan Tinggi Berbasis Web (Studi Kasus: Universitas Siliwangi)," Jurnal Edukasi dan Penelitian Informatika (JEPIN), vol. 3, no. 2, pp. 14-20, 122017.

[2] D. Sugiono, Komunikasi Data dan Interface, Malang: Kementerian Pendidikan \& Kebudayaan, 2013.

[3] S. Sukaridhoto, Komunikasi Data dan Komputer, Surabaya: Politeknik Elektronika Negeri Surabaya, 2016.

[4] Q. Liu and X. Sun, "Research of Web Real-Time Communication Based on Web Socket," Int. J. Communications, Network and System Sciences, vol. 5, pp. 797-801, 122012.

[5] S. Chernyi, "The implementation of technology of multi-user client-server applications for systems of decision making support," Metallurgical and Mining Industry, no. 3, 2015.

[6] J.-t. Park, H.-s. Hwang, J.-s. Yun and I.-y. Moon, "Research and Performance Analysis of HTML5 WebSocket for a Real-time Multimedia Data Communication Environment," Advanced Science and Technology Letters, vol. 46, pp. 307-312, 2014.

[7] E. m. A. reyouchi, K. Ghoumid, K. Ameziane and O. E. Mrabet, "Performance Analysis of Round Trip Time in Narrowband RF Networks For Remote Wireless," International Journal of Computer Science \& Information Technology (IJCSIT), vol. 5, no. 5, October 2013. 
Jurnal SIMETRIS, Vol. 9 No. 1 April 2018

ISSN: 2252-4983

[8] R. Tulloh, R. M. Negara and A. N. Hidayat, "Simulasi Virtual Local Area Network (VLAN) Berbasis Software Defined Network (SDN) Menggunakan POX Controller," Jurnal Informatika, Telekomunikasi dan Elektronika, vol. 10, no. 1, November 2015. 